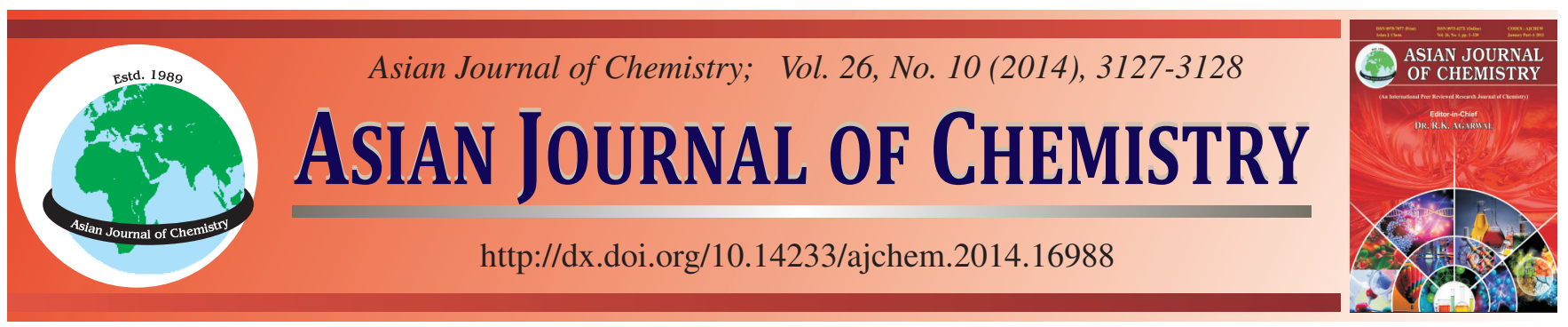

NOTE

\title{
Hydrothermal Synthesis and Crystal Structure of Novel Zn(II) Coordination Polymer Based on 1,3,5-Benzene tricarboxylic Acid and N-Donor Ligands
}

\author{
Guanglong Zou ${ }^{1, *}$, Xuelin Wang ${ }^{2}$, Tingting $\mathrm{Li}^{1}$, ZhiQing FAng ${ }^{1}$ and Bing Xie ${ }^{1, *}$
}

${ }^{1}$ School of Chemistry and Enviromental Science, Guizhou Minzu Univeristy, Guiyang 550025, P.R. China

${ }^{2}$ School of Science, Guizhou Minzu University, Guiyang 550025, P.R. China

*Corresponding authors: E-mail: scesgzmu@126.com

Received: 6 January 2014;

Accepted: 13 February 2014;

Published online: 10 May 2014;

AJC-15197

In this paper, a new zinc(II) coordination polymer with 4,4'-bis(imidazolyl)biphenyl (bib) and 1,3,5-benzene tricarboxylic acid ( $\mathrm{H}_{3}$ bct) has been prepared by hydrothermal synthesis and characterized by single-crystal X-ray diffraction, IR and EA. Complex, $\left(\left[\mathrm{Zn}\left(\mathrm{H}_{2} \mathrm{bct}\right)\left(\mathrm{H}_{2} \mathrm{O}\right)_{2}\right]_{\mathrm{n}} \cdot\left(\mathrm{H}_{2} \mathrm{bct}\right) \cdot(\mathrm{bib})\right\}_{\mathrm{n}}(\mathbf{1})$, is triclinic, space group $\mathrm{P}-1$ with $\mathrm{a}=7.227(5), \mathrm{b}=12.081(5), \mathrm{c}=15.562(5) \AA, \beta=87.780(5)^{\circ}$, $\mathrm{V}=1280.2(11) \AA^{3}, \mathrm{Z}=1, \mathrm{Mr}=1260.29, \mathrm{Dc}=1.635 \mathrm{~g} / \mathrm{cm}^{3}$ and $\mathrm{F}(000)=648$. The final refinement gave $\mathrm{R}=0.0454$ and $\mathrm{wR}=0.0497 \mathrm{for}$ 5127 reflections with $\mathrm{I}>2 \sigma(\mathrm{I})$. X-ray diffraction analysis reveals that the complex $\mathbf{1}$ displays a three-dimensional supramolecular structure via hydrogen bonds.

Keywords: Zn(II), Coordination polymer, 1,3,5-Benzene tricarboxylic acid.

Self-assembly processes involving metal ions and welldesigned organic ligands have attracted considerable attention currently in the field of supramolecular chemistry and crystal engineering from the viewpoints of the development of new materials with unique electronic, magnetic, catalytic and optical properties ${ }^{1-4}$. It is well-known that organocarboxylate exhibit various network topologies and remarkable prospect, therefore the construction of coordination polymers using metal ions and anionic $\mathrm{O}$-donor ligands is one of the hotspot in the crystal engineering field. In addition, the prospect of second organic into a reaction system provides further impetus for research on metal-organic supramolecular frameworks. Among the second organic ligands, the neutral imidazolecontaining ligands are often used ${ }^{5-11}$.

Based on the above mentions, we used the 1,3,5-benzene tricarboxylic acid and 4,4'-bis(imidazolyl)biphenyl to construct a new $\mathrm{Zn}$ (II) coordination polymer. The title complex displays a three-dimensional supramolecular structure via hydrogen bonds.

All reagents and solvents employed were commercially available and used without further purification. Elemental analysis was carried out on a Carlo Erba 1106 full-automatic trace organic elemental analyzer. FT-IR spectra were recorded with a Bruker Equinox 55 FT-IR spectrometer as a dry $\mathrm{KBr}$ pellet in the $4000-400 \mathrm{~cm}^{-1}$ range.

\section{Synthesis}

A mixture of $\mathrm{Zn}\left(\mathrm{NO}_{3}\right)_{2} \cdot 6 \mathrm{H}_{2} \mathrm{O}(0.149 \mathrm{~g}, 0.5 \mathrm{mmol})$, bib $(0.143 \mathrm{~g}, 0.5 \mathrm{mmol}), \mathrm{H}_{3}$ bct $(0.105 \mathrm{~g}, 0.5 \mathrm{mmol})$ and deionized water $(12 \mathrm{~mL})$ was sealed in a $25 \mathrm{~mL}$ Teflon-lined stainless steel vessel and heated at $120^{\circ} \mathrm{C}$ for $48 \mathrm{~h}$ and cooled to room temperature. The colorless block crystals were obtained and washed with alcohol for several times (Yield: $41 \%$ based on $\mathrm{Zn})$. Anal. Calc. for $\mathrm{C}_{54} \mathrm{H}_{42} \mathrm{~N}_{4} \mathrm{O}_{28} \mathrm{Zn}$ : C, 51.46; H, 3.36; N, 4.45 . Found: C, 51.45; H, 3.35; N, 4.46. IR: 3314 br, 1604 s, 1507 s, $1421 \mathrm{~m}, 1336 \mathrm{~m}, 1217 \mathrm{~m}, 1112 \mathrm{~m}, 1008$ m, 937 m, 803 m, $798 \mathrm{~m}$.

X-ray crystallography: Single crystal X-ray diffraction analyses of complex $\mathbf{1}$ were carried out on a Bruker SMART APEXII CCD diffractometer equipped with a graphite monochromated $\mathrm{MoK}_{\alpha}$ radiation $(\lambda=0.71073 \AA$ ) by using a $\omega$-scan mode. Empirical absorption correction was applied using the SADABS programs ${ }^{12}$. All the structures were solved by direct methods and refined by full-matrix least-squares methods on $\mathrm{F}^{2}$ using the program SHEXL $97^{13}$. All non-hydrogen atoms were refined anisotropically. The hydrogen atoms were located by geometrically calculations and their positions and thermal parameters were fixed during the structure refinement. Selected bond and angle parameters are listed in Table-1.

The structure of complex $\mathbf{1}$ is determined by X-ray singlecrystal diffraction with system space group. The asymmetric 


\begin{tabular}{|c|c|c|c|}
\hline \multicolumn{4}{|c|}{$\begin{array}{c}\text { TABLE-1 } \\
\text { SELECTED BOND LENGTHS }(\AA) \\
\text { AND ANGLES }\left({ }^{\circ}\right) \text { FOR COMPLEX } 1\end{array}$} \\
\hline \multicolumn{4}{|c|}{ Compound 1} \\
\hline $\mathrm{Zn}(1)-\mathrm{O}(1 \mathrm{w})$ & $2.1334(18)$ & $\mathrm{Zn}(1)-\mathrm{O}(1)$ & $2.0437(17)$ \\
\hline $\mathrm{Zn}(1)-\mathrm{O}(2 \mathrm{w})$ & $2.126(2)$ & $\mathrm{O} 2 \mathrm{w}-\mathrm{Zn} 1-\mathrm{O}(1 \mathrm{w})$ & $91.11(7)$ \\
\hline $\mathrm{O}(1)-\mathrm{Zn}(1)-\mathrm{O}(1 \mathrm{w})$ & $87.06(7)$ & $\mathrm{O}(1)-\mathrm{Zn}(1)-\mathrm{O} 2 \mathrm{w}$ & $91.73(6)$ \\
\hline
\end{tabular}

unit of complex 1 consists of one crystallographically independent $\mathrm{Zn}$ (II) center, one coordinated $\mathrm{H}_{2} \mathrm{btc}^{-}$, two coordinated water molecules, one free $\mathrm{H}_{2}$ bct ${ }^{-}$and a half of free bimb molecule. As shown in Fig. 1, the $\mathrm{Zn}$ (II) is coordinated by two carboxylate oxygen atoms from two different $\mathrm{H}_{2}$ btc ${ }^{-}$ligands and four oxygen atoms from four coordinated water molecules in an octahedral geometry. Fig. 2 shows the 3D supramolecular architecture of complex1. There exist abundant hydrogenbonding interactions between uncoordinated carboxyate oxygen atoms and the coordinated water molecules. The guest molecules distribute in the pore of 3D supramolecular structure.

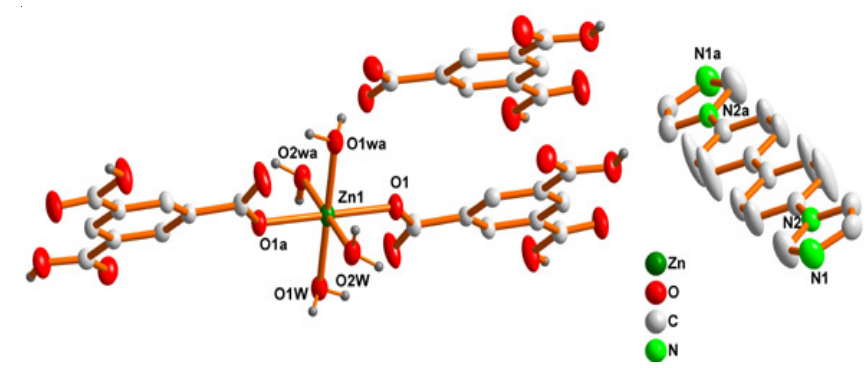

Fig. 1. Coordination environment of $\mathrm{Zn}$ (II) ion

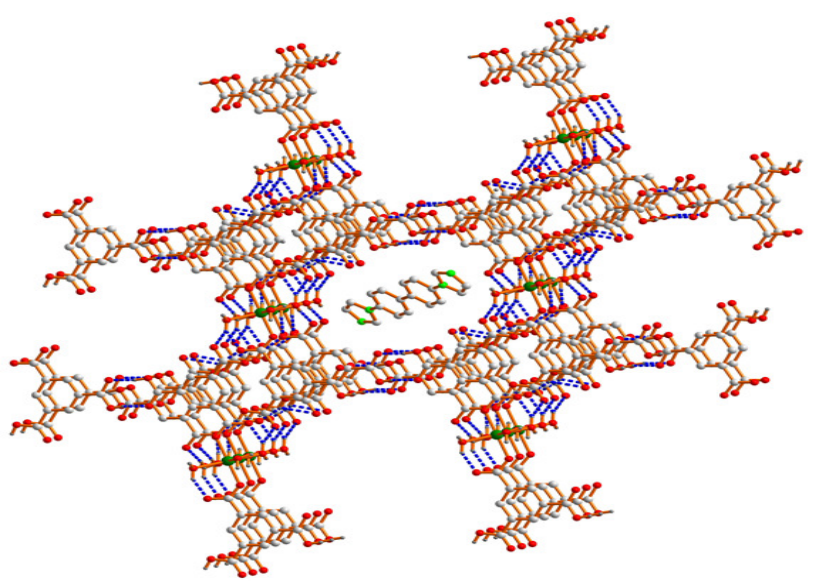

Fig. 2. Packing diagram of complex $\mathbf{1}$

\section{ACKNOWLEDGEMENTS}

The authors gratefully acknowledged the financial support of Scientific Research Foundation of Guizhou Minzu Univeristy (GZMU-201301) and Joint Foundation between GZST and GZMU (LKM201305) and Natural Science Foundation of China (No. 21363004 and 21362005).

\section{REFERENCES}

1. J.Y. Lee, O.K. Farha, J. Roberts, K.A. Scheidt, S.T. Nguyen and J.T. Hupp, Chem. Soc. Rev., 38, 1450 (2009).

2. K. Kim, J.S. Seo, D. Whang, H. Lee, S.I. Jun, J. Oh and Y.J. Jeon, Nature, 404, 982 (2000).

3. S. Kitagawa, J.I. Noro and T. Nakamura, Chem. Commun. (Camb.), 701 (2006)

4. N.L. Rosi, M. Eddaoudi, D.T. Vodak, J. Eckert, M. O'Keeffe and O.M. Yaghi, Science, 300, 1127 (2003).

5. S.S. Kaye, A. Dailly, O.M. Yaghi and J.R. Long, J. Am. Chem. Soc., 129, 14176 (2007).

6. D. Sun, D.J. Collins, Y. Ke, J.L. Zuo and H.C. Zhou, Eur. Chem. J., 12, 3768 (2006).

7. L. Yan, Q. Yue, Q.X. Jia, G. Lemercier and E.Q. Gao, Cryst. Growth Des., 9, 2984 (2009).

8. J. Ni, L.Y. Zhang, H.M. Wen and Z.N. Chen, Chem. Commun. (Camb.), 3801 (2009).

9. C. Kachi-Terajima, K. Yanagi, T. Kaziki, T. Kitazawa and M. Hasegawa, Dalton Trans., 40, 2249 (2011).

10. X.L. Wang, C. Qin, E.B. Wang, L. Xu, Z.M. Su and C.W. Hu, Angew. Chem. Int. Ed., 43, 5036 (2004).

11. S.-S. Chen, P. Wang, S. Takamizawa, T. Okamura, M. Chen and W.-Y. Sun, Dalton Trans., 43, 6012 (2014).

12. A.X.S. Bruker, SAINT Software Reference Manual, Madison, WI (1998).

13. G.M. Sheldrick, SHELXTL NT Version 5.1; Program for Solution and Refinement of Crystal Structures, University of Göttingen, Germany (1997). 